\title{
2019-nCoV effects, transmission and preventive measures: an overview
}

\author{
R. Jegan ${ }^{1}$ (1) • P. Rajalakshmy ${ }^{2}$ P. Subha Hency Jose ${ }^{1}$ - W. S. Nimi ${ }^{3}$
}

Received: 14 May 2020 / Accepted: 20 November 2020 / Published online: 7 January 2021

(C) Springer-Verlag GmbH Germany, part of Springer Nature 2021

\begin{abstract}
Aim COVID-19 has led to a global crisis not only in the health sector but also in the economic, social and education sectors, as well as the lives of common man. This paper reviews the origin, characteristics and transmission of the SARS-CoV-2 Virus and the preventive measures adopted by the world's nations to curb the effects of the pandemic.

Subjects and methods The temporal and spatial profile of the COVID-19 spread is highly dynamic and is progressively changing at a rapid pace. This article is an attempt to mitigate the pandemic threat by sharing the review outcome from an extensive literature survey on recent articles on COVID-19 and its impact.

Results Statistical analysis presented by the World Health Organization and other health organizations explicitly indicates that optimized support and care extended to infected persons is the key to therapy, and the clinical effectiveness of alternative techniques is still under study. Though there have been announcements on the discovery of drugs for the virus, the authenticity of these reports are yet to be verified.

Conclusion Based on the review, it can be inferred that it is important to boost one's immune system and to stay healthy by developing healthy habits of food intake, sleep, exercise, personal hygiene and so on. Practicing social distancing with a selfmotivated attitude will help to control the virus to a large extent. The current situation also demands a great sense of responsibility of people towards society by protecting oneself from the virus in order to protect the society one lives in.
\end{abstract}

Keywords COVID-19 $\cdot$ Pandemic $\cdot$ Immune system $\cdot$ WHO $\cdot$ SARS

\section{Introduction}

Coronaviruses (CoVs) are a large group of viruses that can be seen using powerful microscopes. The name "corona," which means "crown," comes from the shape of the virus. These viruses are found to infect a wide range of mammals and birds. Some types of viruses regularly cause mild respiratory disorders in people. As such, coronaviruses are not new, but the virus that causes coronavirus disease 2019 (COVID-19) is

R. Jegan

19.jegan@gmail.com

1 Department of Biomedical Engineering, Karunya Institute of Technology and Sciences, Coimbatore, India

2 Department of Robotics Engineering, Karunya Institute of Technology and Sciences, Coimbatore, India

3 Department of Biomedical Engineering, Karunya Institute of Technology and Sciences, Coimbatore, India novel, and is called severe acute respiratory syndrome coronavirus 2 (SARS-CoV-2), which is the third of its kind since 2002. These viruses were proven to originate from bats, and developed the ability to jump between species, which gradually led to the virus being transmitted between people, and that is how it came to be the pandemic that the whole world is experiencing now. The first of these viruses was the severe acute respiratory syndrome (SARS) that emerged in Guangdong, China in 2002. The second type emerged in the Middle East in 2012 and was called Middle East respiratory syndrome (MERS). Most recently,- SARS-CoV-2 emerged in Wuhan, China. Viruses must necessarily live in other cells, and they replicate themselves in those cells and go on to infect other cells in the body. The signs and symptoms of the viral infections vary widely, and so do the diagnostic techniques used. In health care networks, there are many diseases that have been treated well by doctors and medical personnel in very effective ways. Basically, the respiratory syndrome due to the coronavirus is not highly complicated and is not considered fully pathogenic to the world population. The different 
families of coronavirus listed in the literature are generally found to affect the human respiratory system associated with common cold issue (Ceraolo and Giorgi 2020; Cui et al. 2019). But in 2003, it was identified that a coronavirus caused a severe acute respiratory syndrome in humans, and it was noted that it could also increase to epidemic proportions. The literature reveals that in 2012, a new coronavirus affected humans which was considered to be a global threat (Sifuentes Rodriguez and Palacios-Reyes 2020). Recently, in December 2019 , a patient with respiratory problem was reported in Wuhan, Hubei province, China. The patient was tested and diagnosed with a disease very similar to normal pneumonia. Due to severe respiratory issues, it was later identified as severe acute respiratory syndrome coronavirus (Huang et al. 2020). It was identified by the Chinese Center for Disease Control and Prevention (CDC) by patient clinical data from a throat swab sample. The World Health Organization (WHO) named this virus 2019-nCoV and declared a public health emergency in January 2020 due to the spread of the coronavirus.

Analysis of the effects of coronavirus disease 209 shows that it mainly causes symptoms of pneumonia, which is very similar to SARS and MERS. Currently, the main symptoms seen in patients infected with 2019-nCoV are fever, cough, myalgia, fatigue, expectoration, headache and gastrointestinal symptoms such as diarrhea (Huang et al. 2020). In general terms, coronaviruses are positive-stranded RNA viruses. Basically, the coronavirus family comprises four main genera, which include Alpha-CoV, Beta-CoV, Delta-CoV and Gamma-CoV. The new 2019-nCoV belongs to the Beta$\mathrm{CoV}$ genus and to the subgenus Sarbecovirus (Lu et al. 2020). The physical structure of this virus is round in shape with 60-140 nm diameter. The International Committee on Taxonomy of Viruses (ICTV) named this virus SARS-CoV2, and the disease it causes, COVID-19 (Lai et al. 2020a). The adverse impact of this virus has rapidly spread across all countries and has cost millions of precious lives. The transmission of the virus from one host to the next is mainly through infected respiratory droplets and though people who have repeated contact with the affected person. It is reported that the time from infection of the human body with the coronavirus to symptom identification can be up to 14 days (incubation period). This novel coronavirus can result in multi-organ infections in various animals and humans, specifically respiratory tract infections, ultimately leading to respiratory failure and death. Therefore, it is necessary to prevent the spread of this virus among the human population because it has a direct impact on both global health and the global economy.

COVID-19 is considered novel not only because of the novel coronavirus, but more so due to the context in which it manifests itself. The world today is extremely globalized, and the economy and social welfare of the world's nations largely depend on global supply chains that span the entire world, which in turn calls for frequent international travel and mobility, resulting in exponential spread of the virus throughout the world. The globalization of supply chains explicitly implies that most countries depend upon each other for consumer products for their everyday consumption, health care needs, staple food, production, research and development. The spread of COVID-19 has led countries to close borders and totally curb international travel to keep the disease contained, and hence there is a shortage of essential supplies such as pharmaceutical products, gloves and masks.

The SARS-CoV-2 virus does not discriminate whom it infects in terms of age, gender, cast, creed or community. But the current situation shows that social privilege and living standards are extremely important in determining the worst impact of the pandemic. This is vividly understood by the entrenched inequality in the impact of the pandemic in various cities within and across countries. The political administration of a particular country also has a very important role to play in curbing the effect of the pandemic. Recently, COVID-19 has affected India in many areas including politics, the economy, external affairs, security law, science, society, culture, education, travel and tourism. The gross domestic product has decreased by $10 \%$. India has already faced three recessions, and it is reported that this is the worst yet. The face of the Indian laborer has changed tremendously. The Centre for Monitoring Indian Economy has reported that the unemployment rate of Indian workers has reached $23 \%$. Industrial production and exports have decreased and resulted in an economic downturn. The government of India has taken all the essential steps to guarantee that all are well equipped to confront the hazard posed by COVID-19. The most significant way to prevent the multiplication of the virus locally is to provide citizens with the right information and ensure that precautions are being taken in accordance with the advisories being issued by the Ministry of Health and Family Welfare.

The state of Kerala in the southern part of India has made global headlines for their highly proactive approach in handling the pandemic throughout the state, what has now become popularly known as the 'Kerala Model' in combating COVID-19. In the words of the Health Minister of Kerala, K.K. Shailaja, who spearheaded the state's COVID-19 response, the state has adopted a strategy primarily focused on the WHO's "test, trace, isolate and support" protocols. In spite of being the state to record the first case of COVID-19 in the country following the return of Indians from the epicenter of the virus in Wuhan, China, the state under the stewardship of the government and health sector was able to effectively flatten the curve during the first phase of the outbreak.

Another typical issue faced by administrators in India is the situation of the migrant workers. In addition to various working conditions and pay, many do not have legal papers and documentation or any kind of social security, and fear deportation. This prevents them from seeking medical care when 
they need it most. They face detention in facilities that are hotbeds of coronavirus infection. In India, hundreds of thousands of migrant workers are at risk. With the short notice period of 21-day lockdown, they had no way to go back to their villages, and they do not have safe places to stay in the cities. They do not have food or wages, and they are scared and desperate, especially worried about their children. Many started walking to their villages with their children for 2 to 3 days. Finally, the government helped them to arrange transportation facilities to their home towns and thus mitigate the issue. Many countries like India have taken immediate action to curb the spread of coronavirus, which includes constructing a new hospital within 10 days, lockdown of the city, avoiding public gathering places such as museums, markets, churches and theaters, closing schools and universities, allowing employees to work remotely, monitoring zone-wise coronavirus cases, cleaning public places, restricting travelers from other countries by suspending flight services, and converting educational institutions to hospitals with all medical facility, with imposed lockdown throughout the country. The government of India also took various measures to handle the situation by allotting extra funding for the states and for health sectors. The state governments announced a number of financial assistance measures for all families, including various relief packages. Rice, wheat, cooking oil and sugar were distributed free of charge to families. The government also released funds for research to find medicine/vaccine for the coronavirus.

In the current scenario, due to lack of sufficient medical facilities and the fact that no medicines and antibiotics are available, the most important method that can be adopted to stop this virus from spreading is to follow the safety measures prescribed by WHO and various government and health organizations, such as wearing a medical mask, being exposed to appropriate rest and ventilation, avoiding unnecessary travel to crowded places, drinking plenty of water and consuming healthy food. This paper provides necessary information on the various effects, transmission and preventive measures for this novel coronavirus that will be of great help to the public in order to understand and manage the situation very effectively. The remainder of the paper is organized as follows: Section 2 presents a brief overview of methods used for understanding the 2019-nCoV and also presents the statistical analysis of its effects around the world. Section 3 provides the details of various research carried out on controlling the spread of this virus.

\section{Methods}

The literature published on the virus highlights the current effects and transmission models of 2019-nCoV among the human population. The purpose of this article is to provide an efficient and clear prospective analysis of the novel coronavirus. The data available on various research platforms have been collected and compiled to provide useful information on the virus to the public.

\section{Primary sources and origination}

An initial study of literature reveals that the virus originates mainly from snakes (Ji et al. 2020) and that the virus model is very close to that of bat coronavirus, as stated by the Wuhan Institute of Virology. But there has been no study on the main source of the virus. The primary sources and transmission model of this virus from one person to another need to be analyzed in order to determine preventive measures that need to be adopted in the future. Studies that are carried out also suggest that racoon dogs, civets and pangolins are hosts for the virus (Kan et al. 2005; Xu et al. 2020). The origin of this novel virus began in the region of Wuhan, China. In late December 2019, Wuhan experienced the effects of this novel coronavirus among its population. Numerous people have succumbed to the family of the $\beta$ group of viruses (2019nCoV or SARS-CoV-2).

The coronaviruses are typically RNA viruses that enter the human cells when their glycoproteins bind to proteins on the surface of the cell. The SARS-CoV-2 binds to the angiotensinconverting enzyme in human cells with a greater affinity than the virus that caused severe acute respiratory syndrome (SARS) in 2003. This difference in the affinity behavior clearly explains the reason for the highly contagious nature of the novel coronavirus. A team of scientists are at work to test the structure of the virus and how it can be used in the development of antivirals.

\section{Transmission}

Basically, SARS-CoV-2 is transmitted in different ways between people. Firstly, infected people have the virus in their mouths, noses and throats. Droplets that come out of the infected person when they talk, laugh, cough or sneeze enter the mouth, nose or eyes of the other person. The second way that the virus is transmitted is through contact with surfaces that have the virus on them. The respiratory droplets from the infected person may fall on surfaces such as tables, doorknobs, etc., which may in turn be transmitted to another person who comes in contact with the infected surface. This is the reason why frequent washing of hands and cleaning is very important. Wearing a mask is also emphasized to prevent the respiratory droplets from one person being transmitted to another. It is important to understand that SARS-CoV-2 is transmitted very efficiently. It is transmitted between people in such a way that makes it difficult to detect and stop. People tend to be infectious even before they develop symptoms, thus being a transmission medium for the virus even without their knowledge. Hence, contact tracing of symptomatic patients is 
important, especially those who are in close contact. Close contact means those who are within six feet of the patient for $15 \mathrm{~min}$ or more. Six feet is the distance that the respiratory droplets can travel and 15 min indicates that one has been around the infected person long enough to come in contact with the infectious droplets. People who share an environment, like offices, restaurants, etc., with the infected person are at some risk for infection themselves. Certain living conditions like group homes and dormitories also pose a high risk of transmission. Since COVID-19 is a new disease and no vaccine has yet been invented, the best way to mitigate the impact of this pandemic is by stopping the transmission. Different studies show that other ways in which the transmission of this virus may occur is through the saliva of infected persons, urine and through the digestive tract, and also by way of aerosols (Wang et al. 2020b; Xiao et al. 2020; Liu et al. 2020). Figure 1 provides a detailed perspective view for transmission of this virus from one person to another person.

According to the scientific platform, the first outbreak of this virus happened in the region of Wuhan, and hence it is considered the origin of the virus. Later, the effect of the virus rapidly spread across the world and has affected millions of people. The detailed number of affected cases of 2019-nCoV is depicted in Fig. 2.

\section{Clinical signs and symptoms}

As an outcome of recent research, it is inferred that 2019nCoV causes the infection in the human body after a specific incubation period of a few days. The previous family of this virus also produced symptoms after 10 days of incubation (Wang et al. 2020a; Chan et al. 2006; Guan et al. 2020). The majority of infected patients have shown symptoms such as fever, cough and respiratory problems. Some patients may also experience headache, loss of taste and muscle pain. The other complications of this virus are acute respiratory distress syndrome, acute cardiac disorder, neurological manifestations, eye secretions and abnormal liver function, which were reported in previous studies (Chen et al. 2020; Mao et al. 2020; Li et al. 2020; Wang et al. 2020c). These symptoms are common to many other diseases. Therefore, diagnosing the presence of 2019-nCoV becomes an essential and challenging task for treating patients with 2019-nCoV. The common symptoms of 2019-nCoV-infected patients are listed in Fig. 3.

\section{Diagnosis of 2019-nCoV}

Many online articles related to 2019-nCoV have been reviewed to compile the diagnostic techniques used to detect the presence of the virus. Based on the characteristics of this novel virus, there are a few methods used in hospitals and health care sectors to diagnose the presence of the virus. In the general case of pneumonia, computed tomography is used by medical personnel to diagnose the infection by capturing the image of the region of infected organs. For 2019-nCoV, certain imaging features are also being considered for diagnosis (Wang et al. 2020c). Conventional laboratory tests are also used by health care personnel to diagnose the viral infection. The proper detection of viral nucleic acid helps to identify the presence of 2019-nCoV, which has key features of very high specificity, reduced sensitivity and high processing time (Wang et al. 2020c).

The methodology adopted for detection mainly depends on the symptoms of the patients. The first step for diagnosis is by performing manual procedures such as collecting information
Fig. 1 Transmission model for 2019-nCoV

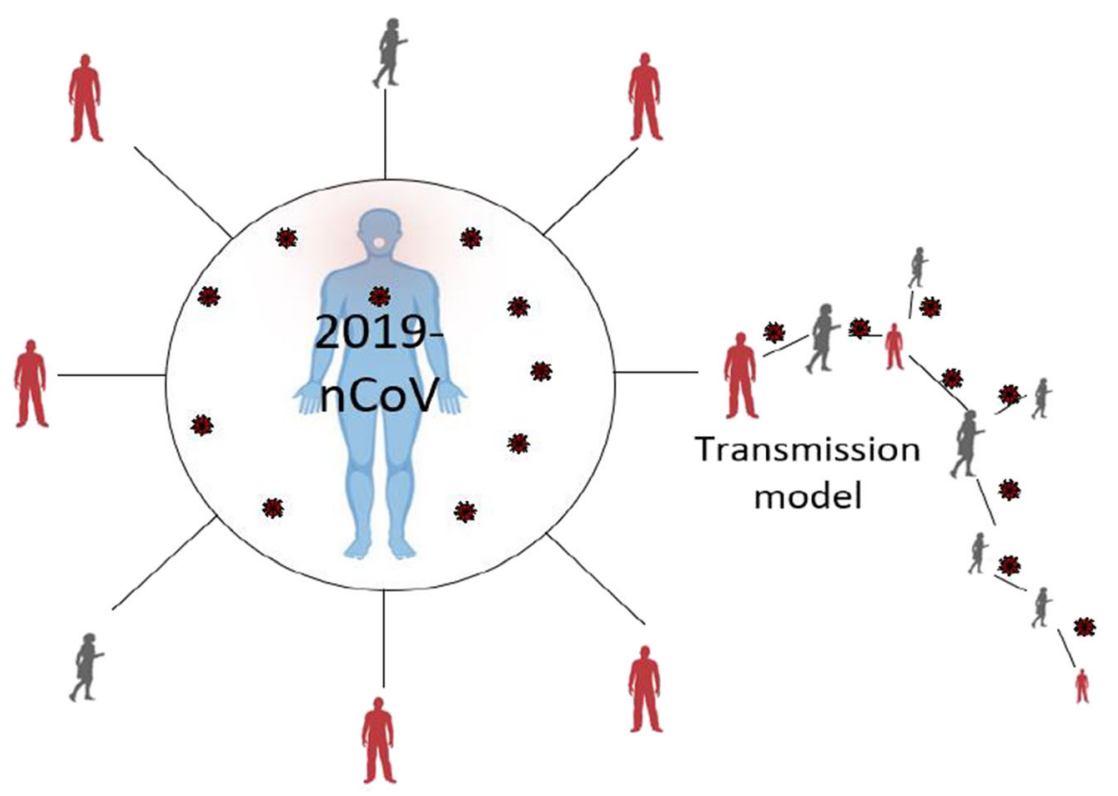




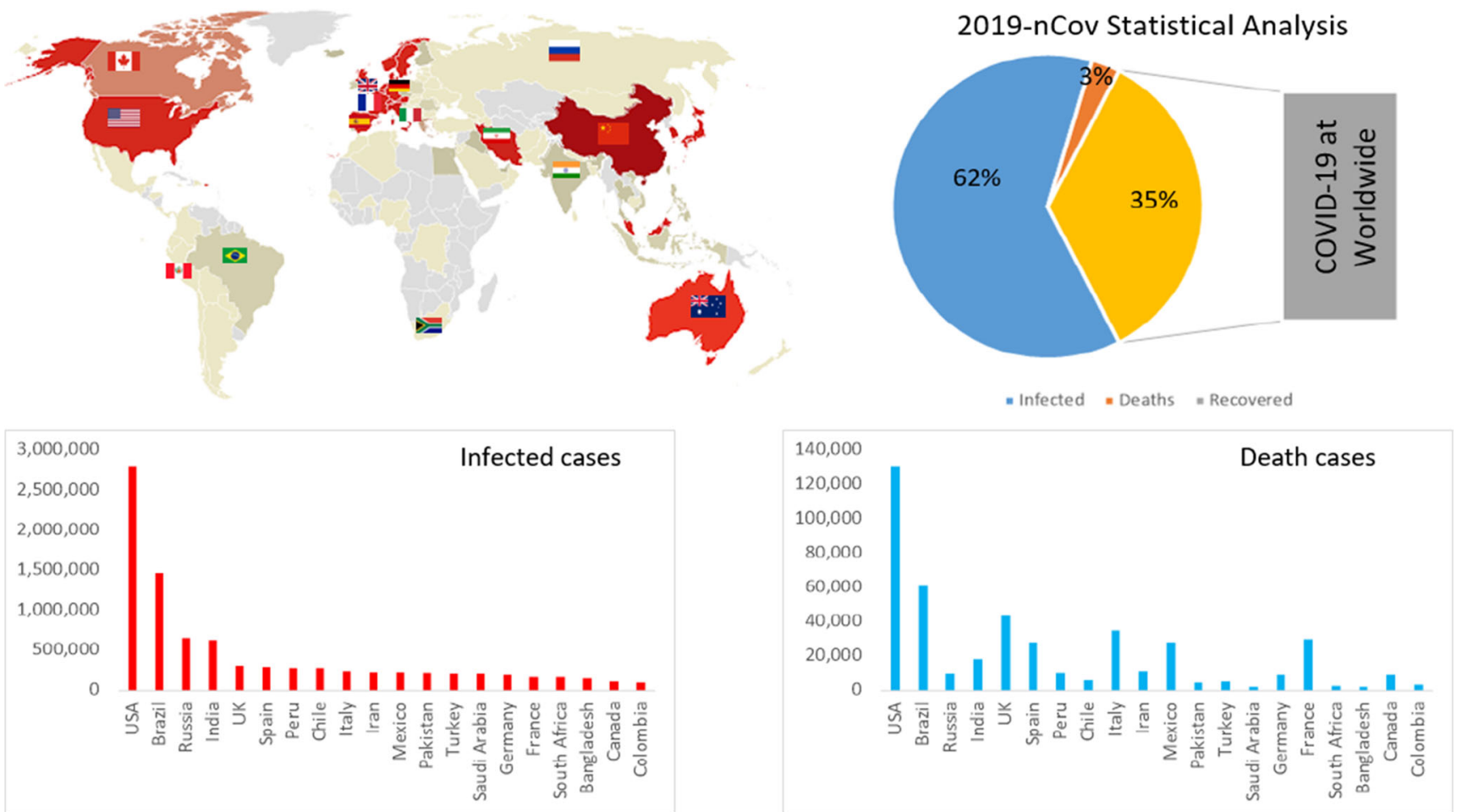

Fig. 2 Statistical results for 2019-nCoV affecting human around the world (top 20 countries) as on 02-07-2020

from the patients which includes their contact details with infected persons and travel history in areas of COVID-19 outbreak. For testing of 2019-nCoV, medical personnel generally use a long swab for nasal sampling and saliva test. Two testing methods are generally used by health care providers, which include a viral test and antibody test to detect the history of viral infection.

\section{Treatment and control methods for 2019-nCoV}

Based on previous studies, there are various treatment methods available to treat the infected person. A few medicines have been recommended by authorized agencies after due testing on viral infection and have proven to be effective in fighting this novel virus. These are Remdesivir, Chloroquine, Arbidol and Kaletra, lopinavir/ritonavir, nucleoside analogues, neuraminidase inhibitors and peptide EK1, which can be used to reduce symptoms in a large number of cases (Holshue et al. 2020; Wang et al. 2020d; Gao et al. 2020a). The most important way to deal with this novel virus is to increase the body's immunity, which largely controls the reaction to this infection. Approved medications that improve immunity are helpful in reducing the ill effects of the virus (Loutfy et al. 2003; Mustafa et al. 2018; Gilardin et al. 2015; Kumar et al. 2013). In the current situation, many people around the world are taking care to improve their health in

Fig. 3 Common symptoms of 2019-nCoV

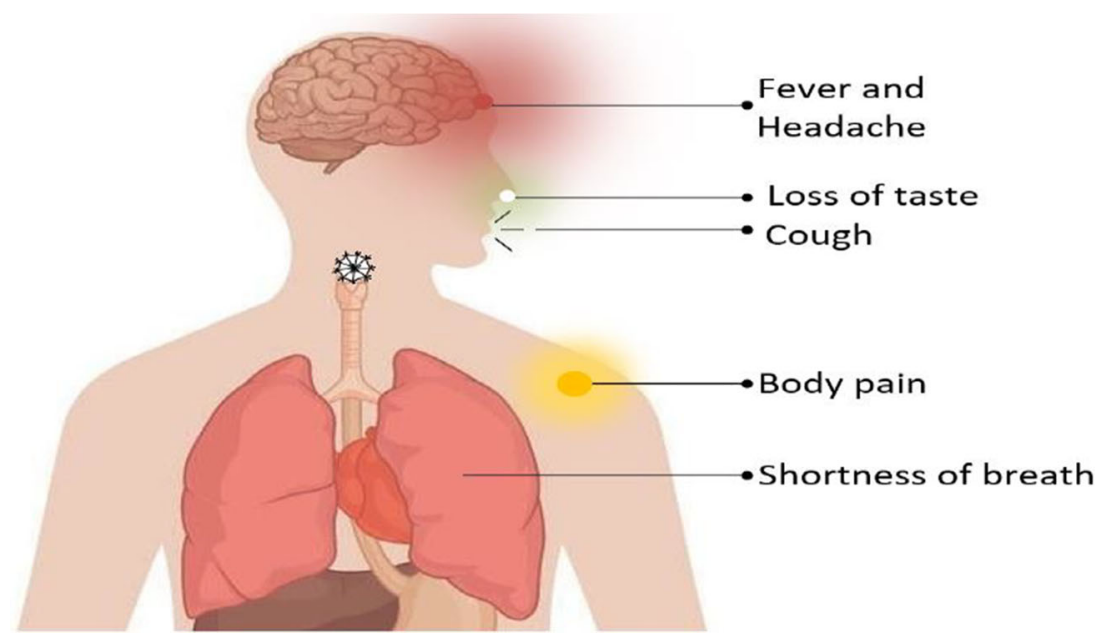


terms of immune power by consuming nutritious food to combat the virus. But reports show that children are very susceptible to this virus in the case of close contact with infected person because of their lower immunity (Bi et al. 2020).

Figure 4 gives the important measures recommended for preventing the spread of the coronavirus from one person to others, which serve as major control parameters when dealing with 2019-nCoV. Recently, researchers have tried different methodologies to understand the nature of the virus in order to develop efficient treatment methods, such as using yeast cells to form the synthetic version of this novel virus genome to treat the disease. Other studies have focused on developing a new scientific method to understand the behavior and treatment of this virus (Liu et al. 2020; Thao et al. 2020; Yin et al. 2020; Srivatsan et al. 2020). The current control measures adopted by various countries are social distancing by lockdown, which has proven to be a very effective control method (Zhang et al. 2020). It is also reported that rapid detection of virus-infected persons and isolating them is a very effective control step for 2019-nCoV (Lai et al. 2020b). Other measures such as washing hands with soap and water frequently, wearing a face mask and hand gloves, avoiding touching surfaces that many people have touched, and drinking hot water also help society prevent infection by this virus.

\section{Research carried out}

Researchers throughout the world have investigated methods to understand the nature of this virus through various experiments. But to date there are no vaccines available for the virus. Therefore, extensive studies are necessary to find a vaccine for the virus to treat infected patients. The experiments carried out by researchers helps to find solutiond in terms of identifying antiviral medicine as shown in Table 1. This can be used to stop and control the effects of $2019-\mathrm{nCoV}$.

\section{Safety precaution}

An extensive study of the characteristics of 2019-nCoV provides necessary guidelines for society. A total of 10,927,867 cases (as on 2 July 2020) were confirmed globally, and millions of people have lost their lives due to this virus. The most important fact is that there is no vaccine available to date to treat the virus. Therefore, it is essential to follow the
Fig. 4 Control measures for preventing coronavirus

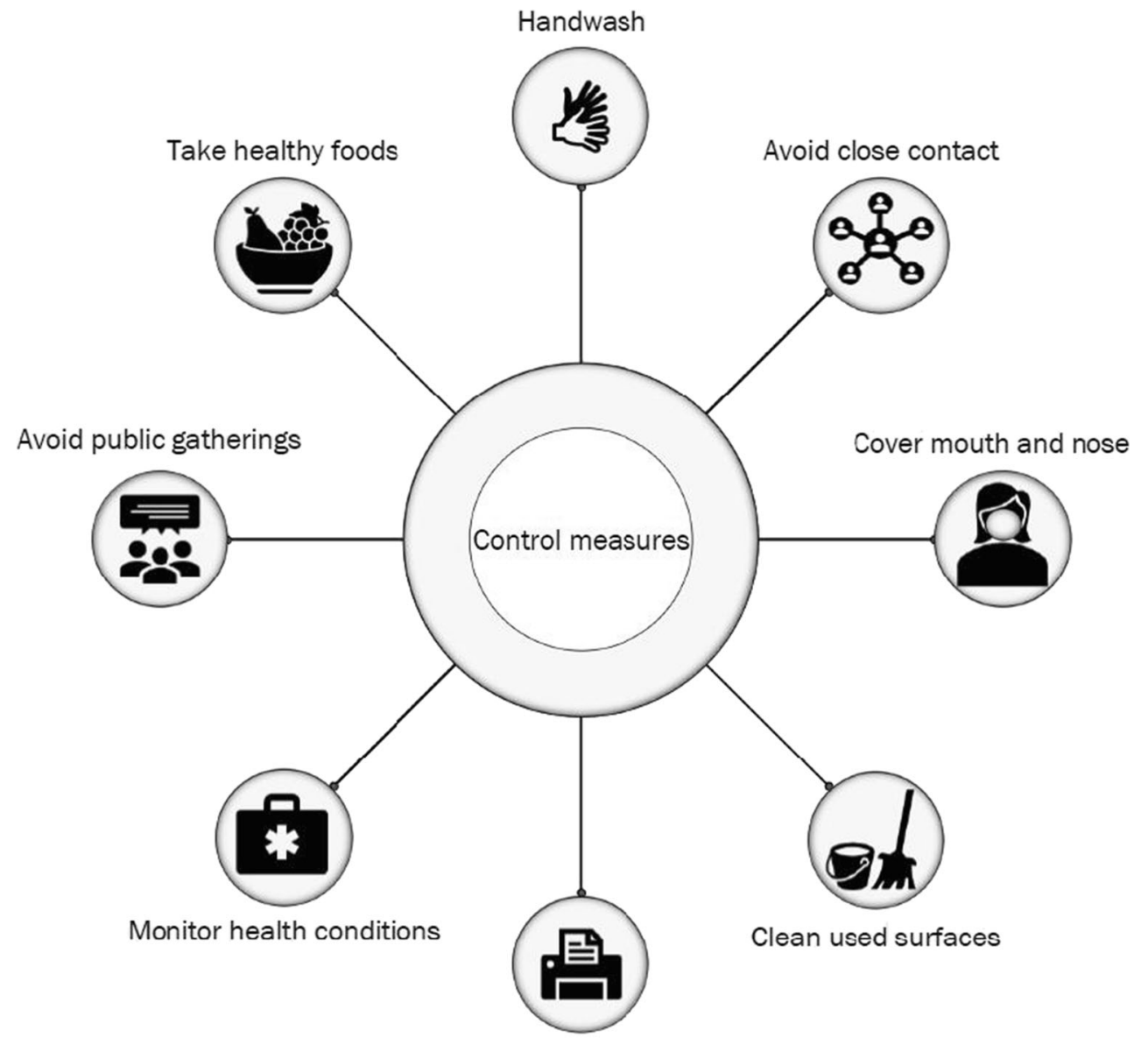

Cover coughs and sneezes 
Table 1 Research carried out during the global 2019-nCoV pandemic

\begin{tabular}{|c|c|c|}
\hline Authors & Research carried out & Purpose \\
\hline (Liu et al. 2020) & Concentration of SARS-CoV-2 RNA in aerosols & Help to control the virus spread \\
\hline (Thao et al. 2020) & Developed a synthetic version of virus genome & Study the biological effects \\
\hline (Yin et al. 2020) & Mapping the 3D shape of the enzyme & Identification of new antiviral compounds \\
\hline (Srivatsan et al. 2020) & Detecting viral RNA in swabs & Genetic testing at centralized laboratories \\
\hline (Hillen Hauke et al. 2020) & Study of the structure of the polymerase & Block polymerase activity by drugs design \\
\hline (Gudbjartsson et al. 2020) & Study of antiviral proteins called interferons & Limit viral replication \\
\hline (Ziegler et al. 2020) & Studied airway cells from people with influenza & Activation of the gene for ACE2 \\
\hline (Wyllie et al. 2020) & Saliva testing & Detection of 2019-nCoV \\
\hline (Lavezzo et al. 2020) & Analyzing potential infectiousness & Suggest strict social distancing \\
\hline (Gao et al. 2020b) & Vaccine development & Treating patients with 2019-nCoV \\
\hline (Cowling et al. 2020) & Surveying different methodologies & Control the spread of coronavirus \\
\hline (Quinlan et al. 2020) & Developing antibodies & Recognize the coronavirus \\
\hline (Chenguang et al. 2020) & Performing plasma treatment & Provide a treatment for virus infection \\
\hline (Blanco-Melo et al. 2020) & Sequencing of viral RNA from tested people & Stop the spread of the virus \\
\hline (Schmid-Burgk et al. 2020) & Developing biological barcode with unique DNA & Analyze more samples per day \\
\hline (Jin et al. 2020) & Screening of viral inhibitors & Treat a disease caused by coronaviruses \\
\hline (Leung et al. 2020) & Detecting coronavirus RNA & Provide safety measures to stop virus spread \\
\hline (Wrapp et al. 2020) & Developing antibodies & Useful in combating coronavirus epidemics \\
\hline (Duan et al. 2020) & Study of plasma treatment & Give treatment for virus infection \\
\hline (Gordon et al. 2020) & Study to identify human proteins & Developing antiviral activity \\
\hline (Ni et al. 2020) & Detection of SARS-CoV-2 & Control the spread of this virus \\
\hline
\end{tabular}

guidelines laid down by government bodies and health care organizations in order to avoid the spread of 2019-nCoV. The safety measures for this virus include maintaining social distancing, avoiding unnecessary travel to crowded places, wearing masks and consuming healthy food. These are very essential steps to prevent the transmission of this novel virus. These safety methods are very appropriate because of the way the 2019-nCoV is transmitted from one person to another person. The infected person with this virus should be immediately isolated and treated. This will go a long way in helping society to control the spread of the virus. Many countries have already constructed a large number of hospitals in a matter of just a few days in order to ensure that treatment is available to the large numbers of infected patients. Various approved organizations and committees related to $2019-\mathrm{nCoV}$ have requested that persons who have had contact with infected individuals need to self-quarantine at home. The symptoms for this virus are initiated within 2 to 14 days. The rapid progress of the research on 2019-nCoV will help society successfully deal with this virus. Certain treatment procedures used by health care workers have shown successful results. The large number of patients being completely healed of the virus is proof of this fact. Traditional, indigenous medicines are also used by people to increase the immune power of the body to fight the virus.

According to the World Health Organization, the proper way to control the spread of this virus includes early recognition and successful detection, providing better precautions to all patients. Many countries have faced the serious effects of this virus, in particular the USA, Brazil, Russia, India, Spain, Italy and the UK. The number of confirmed cases around the world due to the virus is given in Fig. 2. Research teams worldwide are investigating the features of COVID-19 and working towards developing a vaccine for treatment, but it is still essential to develop therapeutic options for this viral infection. According to research by the medical community, there is no vaccine available to treat the virus, but there is a possible way to stop the spread of the virus in the human environment. Government bodies all over the world support people in controlling the spread of 2019-nCov by measures including lockdowns, infected patient isolation, economic and day life support, and providing a necessary first stage treatment to reduce fever and cough. Based on the information given in this paper, it can be suggested that only social distancing and self-quarantine are the right choice for people until the development of a suitable vaccine for this virus.

\section{Conclusion}

This study focused on existing reviews of 2019-nCoV effects, transmission and preventive measures among the human 
population. The disease induced by this novel virus has become a very serious issue in the world's population. Also, the dominating behavior of this virus in terms of transmission through close contact and droplets creates many problems in human life. This review provides statistical information on affected patients globally, highlights the existing research carried out to develop suitable therapeutic techniques to treat the virus, and also provides various safety measures. Moreover, the information available in this paper helps society to understand and follow important safety measures to remain safe and healthy.

Funding This paper is not funded by any funding source.

\section{Compliance with ethical standards}

Conflict of interest There are no potential conflicts of interest.

Ethical approval and informed consent The authors confirm that this study did not involve human or animal subjects or tissue.

\section{References}

Bi Q, Wu Y, Mei S, Ye C et al (2020) Epidemiology and transmission of COVID-19 in 391 cases and 1286 of their close contacts in Shenzhen. China: a retrospective cohort study. Lancet 20(8):911919. https://doi.org/10.1016/S1473-3099(20)30287-5

Blanco-Melo D, Nilsson-Payant BE, Liu W-C et al (2020) Imbalanced host response to SARS-CoV-2 drives development of COVID- 19. Cell 181:1036-1045

Ceraolo C, Giorgi FM (2020) Genomic variance of the 2019-nCoV coronavirus. J Med Virol 92(5):522-528. https://doi.org/10.1002/jmv. 25700

Chan PKS, Tang JW, Hui DSC (2006) SARS: clinical presentation, transmission, pathogenesis and treatment options. Clin Sci 110: 193-204. https://doi.org/10.1042/CS20050188

Chen N, Zhou M, Dong X et al (2020) Epidemiological and clinical characteristics of 99 cases of 2019 novel coronavirus pneumonia in Wuhan, China: a descriptive study. Lancet 395:507-513. https://doi.org/10.1016/S0140-6736(20)30211-7

Chenguang S, Wang Z et al (2020) Treatment of 5 critically ill patients with COVID-19 with convalescent plasma. JAMA 323(16):15821589. https://doi.org/10.1001/jama.2020.4783

Cowling BJ, Ali ST et al (2020) Impact assessment of nonpharmaceutical interventions against coronavirus disease 2019 and influenza in Hong Kong: an observational study. Lancet Public Health 5(5):e279-e288. https://doi.org/10.1016/S2468-2667(20) 30090-6

Cui J, Li F, Shi Z-L (2019) Origin and evolution of pathogenic coronaviruses. Nat Rev Microbiol 17(3):181-192. https://doi.org/ 10.1038/s41579-018-0118-9

Kai Duan, Bende Liu, Cesheng Li. et al (2020) The feasibility of convalescent plasma therapy in severe covid-19 patients: a pilot study. medRxiv. https://doi.org/10.1101/2020.03.16.20036145

Gao J, Tian Z, Yang X (2020a) Breakthrough: chloroquine phosphate has shown apparent efficacy in treatment of COVID-19 associated pneumonia in clinical studies. Biosci Trends 14(1):72-73. https:// doi.org/10.5582/bst.2020.01047
Gao Q, Bao L, Mao H et al (2020b) Development of an inactivated vaccine candidate for SARS-CoV-2. Science 369(6499):77-81. https://doi.org/10.1126/science.abc1932

Gilardin L, Bayry J, Kaveri SV (2015) Intravenous immunoglobulin as clinical immune-modulating therapy. CMAJ 187:257-264. https:// doi.org/10.1503/cmaj.130375

Gordon DE, Jang GM, Bouhaddou M et al (2020) A SARS-CoV-2 protein interaction map reveals targets for drug repurposing. Nature 583:459-468. https://doi.org/10.1038/s41586-020-2286-9

Guan W-J, Ni Z-y et al (2020) Clinical characteristics of 2019 novel coronavirus infection in China. N Engl J Med 110:193-204. https://doi.org/10.1101/2020.02.06.20020974

Gudbjartsson DF, Agnar H, Hakon J et al (2020) Spread of SARS-CoV-2 in the Icelandic population. N Engl J Med 382:2302-2315. https:// doi.org/10.1056/NEJMoa2006100

Hillen HS, Goran K, Kokic G, Farnung L et al (2020) SStructure of replicating SARS-CoV-2 polymerase. Nature 584: 154-156. https://doi.org/10.1038/s41586-020-2368-8

Holshue ML, MPH C, MPH DB et al (2020) First case of 2019 novel coronavirus in the United States. N Eng J Med 382(10):929-936. https://doi.org/10.1056/NEJMoa2001191

Huang C, Wang Y, Li X et al (2020) Clinical features of patients infected with 2019 novel coronavirus in Wuhan, China. Lancet 395:497506. https://doi.org/10.1016/S0140-6736(20)30183-5

Ji W, Wang W, Zhao X et al (2020) Homologous recombination within the spike glycoprotein of the newly identified coronavirus may boost cross-species transmission from snake to human. J Med Virol 92: 433-440. https://doi.org/10.1002/jmv.25682.

Jin Z, Du X, Xu Y et al (2020) Structure of $\mathrm{M}^{\text {pro }}$ from SARS-CoV-2 and discovery of its inhibitors. Nature 582:289-293. https://doi.org/10. 1038/s41586-020-2223-y

Kan B, Wang M et al (2005) Molecular evolution analysis and geographic investigation of severe acute respiratory syndrome coronaviruslike virus in palm civets at an animal market and on farms. J Virol 79(18):11892-11900 https://jvi.asm.org/content/79/18/11892

Kumar V, Jung Y-S, Liang P-H (2013) Anti-SARS coronavirus agents: a patent review (2008-present). Expert Opin Therapeutic Patents 23(10): 1337-1348

Lai CC, Shih T-P, Ko W-C, Tang H-J, Hsueh P-R (2020a) Severe acute respiratory syndrome coronavirus 2 (SARS-CoV-2) and coronavirus disease-2019 (COVID-19): the epidemic and the challenges. Int J Antimicrob Agents 55(3):105924. https://doi.org/10.1016/j. ijantimicag.2020.105924

Lai S, Ruktanonchai NW, Zhou L et al (2020b) Effect of nonpharmaceutical interventions to contain COVID-19 in China. Nature 585:410-413. https://doi.org/10.1038/s41586-020-2293-x

Lavezzo E, Franchin E, Ciavarella, C et al (2020) Suppression of a SARS-CoV-2 outbreak in the Italian municipality of Vo'. Nature 584:425-429. https://doi.org/10.1038/s41586-020-2488-1

Leung NHL, Chu DKW et al (2020) Respiratory virus shedding in exhaled breath and efficacy of face masks. Nat Med 26:676-680. https://doi.org/10.1038/s41591-020-0843-2

Li Z, Wu M, Yao J, et al (2020) Caution on kidney dysfunctions of 2019nCoV patients. medRxiv: the preprint. https://doi.org/10.1101/2020. 02.08 .20021212

Liu Y, Ning Z, Chen Y et al (2020) Aerodynamic analysis of SARSCoV-2 in two Wuhan hospitals. Nature 582:557-560. https://doi. org/10.1038/s41586-020-2271-3

Loutfy MR, Blatt LM et al (2003) Interferon alfacon-1 plus corticosteroids in severe acute respiratory syndrome: a preliminary study. JAMA 290:3222-3228. https://doi.org/10.1001/jama.290.24.3222

Lu R, Zhao X, Li J et al (2020) Genomic characterization and epidemiology of 2019 novel coronavirus: implications for virus origins and receptor binding. Lancet 395(10224):565-574. https://doi.org/10. 1016/S0140-6736(20)30251-8 
Mao L, Jin H, Wang M et al (2020) Neurologic Manifestations of Hospitalized Patients With Coronavirus Disease 2019 in Wuhan, China. JAMA Neurol 77(6):683-690. https://doi.org/10.1001/ jamaneurol.2020.1127

Mustafa S, Balkhy H, Gabere MN (2018) Current treatment options and the role of peptides as potential therapeutic components for middle east respiratory syndrome (MERS): a review. J Infect Publ Health 11:9-17. https://doi.org/10.1016/j.jiph.2017.08.009

Ling Ni, Fang Ye, Meng-Li Chen, Yu Feng et al (2020) Detection of SARS-CoV- 2 specific humoral and cellular immunity in COVID19 convalescent individuals. Immunity 52:971-977. https://doi.org/ 10.1016/j.immuni.2020.04.023.

Quinlan BD, HuihuiM, Lizhou Z, Yan G et al (2020) The SARS-CoV- 2 receptor-binding domain elicits a potent neutralizing response without antibodydependentenhancement. bioRxiv: the preprint. https:// doi.org/10.1101/2020.04.10.036418

Schmid-Burgk JL, Li D, Feldman D et al (2020) Lamp-Seq: Population scale COVID-19 diagnostics using a compressed barcode space. bioRxiv: the preprint. https://doi.org/10.1101/2020.04.06.025635

Sifuentes Rodriguez E, Palacios-Reyes D (2020) COVID-19: the outbreak caused by a new coronavirus. Bol Med Hosp Infant Mex 77(2):47-53. https://doi.org/10.24875/BMHIM.20000039

Srivatsan S, Han P. D, van Raay K et al (2020) Preliminary support for a "dry swab extraction free" protocol for SARS-CoV-2 testing via RT-Qpcr. bioRxiv. https://doi.org/10.1101/2020.04.22.056283

Thi Nhu Thao T, Labroussaa F, Ebert N et al (2020) Rapid reconstruction of SARS-CoV-2 using a synthetic genomics platform. Nature 582: 561-565. https://doi.org/10.1038/s41586-020-2294-9

Wang D, Hu B, Hu C et al (2020a) Clinical characteristics of 138 hospitalized patients with 2019 novel coronavirus-infected pneumonia in Wuhan, China. JAMA 323(11):1061-1069. https://doi.org/10.1001/ jama.2020.1585

Wang J, Zhao S, Liu M et al (2020b) ACE2 expression by colonic epithelial cells is associated with viral infection, immunity and energy metabolism. medRxiv. https://doi.org/10.1101/2020.02.05. 20020545

Wang L, Wang Y, Ye D et al (2020c) Review of the 2019 novel coronavirus (SARS-CoV-2) based on current evidence. Int J Antimicrobial
Agents 55:105948. https://doi.org/10.1016/j.ijantimicag.2020. 105948

Wang M, Cao R, Zhang L et al (2020d) Remdesivir and chloroquine effectively inhibit the recently emerged novel coronavirus (2019$\mathrm{nCoV}$ ) in vitro. Cell Res 30(3):269-271. https://doi.org/10.1038/ s41422-020-0282-0

Wrapp D, De Vlieger D et al (2020) Structural basis for potent neutralization of beta coronaviruses by single-domain camelid antibodies. Cell 181:1004-1015. https://doi.org/10.1016/j.cell.2020.04.031

Wyllie AL, Fournier J, Massana AC et al (2020) Saliva is more sensitive for SARS-CoV-2 detection in COVID-19 patients than nasopharyngeal swabs. medRxiv. https://doi.org/10.1101/2020.04.16. 20067835

Xiao F, Tang M, Zheng X et al (2020) Evidence for gastrointestinal infection of SARS-CoV-2. Gastroenterology 158(6):18311833.e3. https://doi.org/10.1053/j.gastro.2020.02.055

$\mathrm{Xu} \mathrm{X}$, Chen P, Wang J et al (2020) Evolution of the novel coronavirus from the ongoing Wuhan outbreak and modeling of its spike protein for risk of human transmission. China Life Sci 63(3):457-460. https://doi.org/10.1007/s11427-020-1637-5

Yin W, Mao C et al (2020) Structural basis for inhibition of the RNA dependent RNA polymerase from SARS-CoV-2 by remdesivir. Science 368(6498):1499-1504. https://doi.org/10.1126/science. abc 1560

Zhang J, Litvinova M, Liang Y et al (2020) Changes in contact patterns shape the dynamics of the COVID-19 outbreak in China. Science. 368(6498):1481-1486 https://science.sciencemag.org/content/ early/2020/05/04/science.abb8001

Ziegler CGK, Allon SJ et al (2020) SARS-CoV-2 Receptor ACE2 Is an Interferon-Stimulated Gene in Human Airway Epithelial Cells and Is Detected in Specific Cell Subsets across Tissues. Cell 181(5): 1016-1035.e19. https://doi.org/10.1016/j.cell.2020.04.035

Publisher's note Springer Nature remains neutral with regard to jurisdictional claims in published maps and institutional affiliations. 